\title{
LAETITIA SIMONETTA, La Connaissance par sentiment au XVIII siècle
}

\section{Maria Immacolata Spagna}

\section{(2) OpenEdition \\ Journals}

\section{Edizione digitale}

URL: http://journals.openedition.org/studifrancesi/16361

DOI: 10.4000/studifrancesi. 16361

ISSN: 2421-5856

\section{Editore}

Rosenberg \& Sellier

\section{Edizione cartacea}

Data di pubblicazione: 1 juillet 2019

Paginazione: 159

ISSN: 0039-2944

\section{Notizia bibliografica digitale}

Maria Immacolata Spagna, «LAETITIA SIMONETTA, La Connaissance par sentiment au XVIII ${ }^{e}$ siècle», Studi Francesi [Online], 187 (LXIII | I) | 2019, online dal 01 juillet 2019, consultato il 25 janvier 2021. URL: http://journals.openedition.org/studifrancesi/16361; DOI: https://doi.org/10.4000/studifrancesi. 16361

Questo documento è stato generato automaticamente il 25 janvier 2021.

\section{(†) $\odot$

Studi Francesi è distribuita con Licenza Creative Commons Attribuzione - Non commerciale - Non opere derivate 4.0 Internazionale. 


\title{
LAETITIA SIMONETTA, La Connaissance par sentiment au XVIII siècle
}

\author{
Maria Immacolata Spagna
}

\section{NOTIZIA}

LAETITIA SIMONETTA, La Connaissance par sentiment au XVIII siècle, Paris, Honoré Champion, 2018, «Les Dix-huitièmes siècles» 201, 575 pp.

1 Il volume ripercorre gli autori del xviII secolo che rendono conto del modo in cui alcuni oggetti della conoscenza come i valori morali ed estetici, la cui natura non è né interamente razionale né completamente sensibile, sono conosciuti attraverso il sentimento. Lo studio copre un ampio corpus di scrittori e filosofi, a partire da Malebranche - il primo che, traendo le conseguenze della definizione cartesiana del sentimento quale effetto dell'unione dell'anima e del corpo, introduce l'idea che la conoscenza dell'anima avviene attraverso il sentimento interiore determinando lo sviluppo di una concezione "sensibile" della conoscenza di sé -, per finire con Rousseau, l'ultimo ad avere mantenuto la possibilità di una conoscenza per mezzo del sentimento, prima della rottura kantiana. Da un punto di vista geografico, lo studio si concentra sulla Francia, passando per la filosofia morale ed estetica scozzese.

2 Il volume si struttura in tre parti, che corrispondono a tre oggetti della conoscenza attraverso il sentimento: il sé, la morale e il bello.

3 Nella prima parte, incentrata sulla conoscenza di sé, L. Simonetta sottolinea l'irriducibilità del sentimento interiore alla sensazione e mostra come i sentimenti arrivino pian piano a designare le percezioni sensibili che ci informano sul nostro stato interiore piuttosto che su quello degli oggetti esteriori.

4 La seconda parte mette in evidenza il modo in cui i filosofi del xvIII secolo, che cercano di fondare i principi della virtù sulla ricerca interessata della felicità, regolano la questione della conoscenza degli oggetti della morale. In quest'ottica, l'attenzione si focalizza su tre concezioni morali: quella di Malebranche, di Rousseau e dei filosofi 
scozzesi Shaftesbury e Hutcheson, secondo cui certi oggetti essenziali alla moralità dell'esistenza dell'uomo possono essere conosciuti solo attraverso il sentimento.

Dedicata alla conoscenza estetica, l'ultima parte dell'opera si interessa al modo in cui il sentimento, che si sostituisce in gran parte alla ragione, diventa il principio dell'apprezzamento della bellezza. Pur essendo relativo alla sensibilità dello spettatore, il sentimento del bello è il modo di cogliere l'essenza stessa del fenomeno estetico, il miglior criterio per giudicare il merito delle opere d'arte. Come rileva Simonetta, in alcuni autori, quali Du Bos, Hutcheson e Diderot, il sentimento non è necessario soltanto per conoscere la bellezza ma persino per definirne il suo essere, in quanto l'effetto estetico non esiste al di fuori del sentimento che lo percepisce. Queste riflessioni, uscite dalla sfera artistica, hanno alimentato anche una riflessione filosofica, quella dell'empirismo. In particolare, Condillac, nel percorso di indagine sui progressi compiuti dall'uomo, è costretto ad ammettere che determinati oggetti, per essere conosciuti, devono sfuggire all'analisi e alla spiegazione perché sono gustati o percepiti nel sentimento. È, per eccellenza, il caso della bellezza. Mentre in ambito morale il sentimento appare come un sostegno affettivo alle deduzioni razionali, l'ambito estetico impone il sentimento come l'unico mezzo attraverso il quale l'opera è conosciuta nella sua bellezza o nella sua realtà di opera d'arte. Il giudizio è così trasferito nell'affettività per liberarlo dall'arbitrio della ragione, in campi in cui bisogna giudicare secondo princìpi indimostrabili quali il bene e il bello.

Dalla prima alla terza parte, emerge che la dimensione cognitiva del sentimento è rafforzata, poiché si passa da una semplice informazione su uno stato interiore, da una coscienza immediata e non rappresentativa, a un sentimento rappresentativo dell'oggetto stesso nell'ambito estetico. 